\title{
The sufficient vitamin $D$ and albumin level have a protective effect on COVID-19 infection
}

\author{
Somaieh matin ${ }^{1,2}$. Nasrin Fouladi ${ }^{3,4} \cdot$ Yasamin Pahlevan $^{5} \cdot$ Vahid Asghariazar $^{5,6}$. Soheila Molaei ${ }^{5,7}$. \\ Hamid Afzoun khiavi ${ }^{6} \cdot$ Mohamad Negaresh $^{8} \cdot$ Elham Safarzadeh $^{9}$
}

Received: 15 March 2021 / Revised: 3 July 2021 / Accepted: 7 July 2021 / Published online: 30 July 2021

(c) The Author(s), under exclusive licence to Springer-Verlag GmbH Germany, part of Springer Nature 2021

\begin{abstract}
There is limited information regarding the protective factors of SARS-CoV-2 infection. This research is focused on analyzing the role of vitamin D and albumin in the severity, progression, or possible prevention of COVID-19 infection. In this case-control study, 191 patients and 203 healthy individuals were enrolled. Blood samples were taken to test the albumin and vitamin D levels of both groups. Our results show a direct association of vitamin D deficiency with the infection of COVID-19 and severity. According to our findings, $84.4 \%$ of patients with COVID-19 in this study had vitamin D deficiency. Moreover, the average level of albumin was significantly decreased in those infected patients who had respiratory symptoms. In the present study, a considerable negative correlation was established between the levels of vitamin D and the severity of COVID-19 infection. This reflects on the immunomodulatory and inhibitory nature of vitamin D to the viral replication.
\end{abstract}

Keywords COVID-19 $\cdot$ Vitamin D · Albumin · Coronavirus

Communicated by Erko Stackebrandt.

Elham Safarzadeh

E.safarzadeh@arums.ac.ir

1 Department of Internal Medicine, Imam khomeini hospital, Ardabil University of Medical Sciences, Ardabil, Iran

2 Gastrointestinal and Liver Disease Research Center, Razi Hospital, Guilan University of Medical Sciences, Rasht, Iran

3 School of Medicine and Allied Medical Sciences, Ardabil University of Medical Sciences, Ardabil, Iran

4 Social Determinants of Health Research Center, Ardabil University of Medical Sciences, Ardabil, Iran

5 Deputy of Research and Technology, Ardabil University of Medical Sciences, Ardabil, Iran

6 Immunology Research Center, Ardabil University of Medical Sciences, Ardabil, Iran

7 Pharmaceutical Sciences Research Center, Ardabil University of Medical Sciences, Ardabil, Iran

8 Students Research Committee, School of Medicine, Ardabil University of Medical Sciences, Ardabil, Iran

9 Department of Microbiology, Parasitology, and Immunology, School of Medicine, Ardabil University of Medical Sciences, Ardabil, Iran

$\begin{array}{ll}\text { Abbreviations } \\ \text { ACE-2 } & \text { Angiotensin-converting enzyme-2 } \\ \text { CYP27B1 } & \text { Vitamin D activating enzyme } \\ & 1-\alpha \text {-hydroxylase } \\ \text { VDR } & \text { Vitamin D receptor } \\ \text { NET } & \text { Neutrophil extracellular traps } \\ \text { ROS } & \text { Reactive oxygen species } \\ \text { RT-PCR } & \text { Real-time reverse transcriptase polymerase } \\ & \text { chain reaction } \\ \text { CT } & \text { Computed tomography } \\ \text { GGO } & \text { Ground-glass opacity } \\ \text { ORs } & \text { Odds ratios } \\ \text { VDR } & \text { Vitamin D and its functional receptors } \\ \text { VDRGS } & \text { Vitamin D-related genes }\end{array}$

\section{Introduction}

COVID-19 pandemic has started from Dec 2019 in Wuhan, China and is still ongoing. The disease has been spread all over the world, reported as a major health challenge. SARS CoV-2 is an enveloped, positive sense RNA virus, genetically classified with in family Coronaviridae and genus Betacoronavirus. COVID-19 disease causes pneumonia and ARDS, which leads to the multiorgan failure and become fatal at the later stages. Epithelial cells of lungs and other 
organs of the body have the ACE-2 (Angiotensin-converting enzyme-2) receptors help SARSCoV-2 virus to attach and enter the cells. The systemic hyper-inflammation in the lungs is due to the formation of 'cytokine storm' that could be the cause of respiratory and multiorgan failure with death (Wu and Zheng 2020). The pulmonary fibrosis complication could be the result of this mechanism (Lai et al. 2020).

The specific treatment has not been known for COVID19 until now. The best available antiviral therapies are interferon- $\beta$ and ribavirin-based therapy, which reported having high toxicity and unpredicted outcomes besides high and rapid mortality rate for SARS CoV-2, considered to the urgent requirement of discovering improved COVID-19 treatment (Kupferschmidt and Cohen 2020).

Vitamin D plays a key role in cell proliferation, and differentiation, calcium and phosphate homeostasis, immunemodulatory properties, including interfering with a major group of immune cells such as lymphocytes (B and $T$ cells), dendritic cells, macrophages, and neutrophils, and are related with down- or up-regulation of various pro- or anti-inflammatory cytokines (Baeke et al. 2010; Samuel and Sitrin 2008). Several studies suggest an important impact of vitamin D on viral infections. Immune cells synthesize the metabolite calcitriol-1,25 $(\mathrm{OH}) 2 \mathrm{D}$ has been suggested immunomodulatory characteristics for vitamin D similar to cytokines. Vitamin D activating enzyme $1-\alpha$-hydroxylase (CYP27B1) and vitamin D receptor (VDR) has been shown to be expressed in many cell types such as cells of the immune system. Moreover, vitamin D deficiency may conclude susceptibility to viral rather than bacterial infections, mainly in airborne viral infections (Zittermann et al. 2016).

VDR mediates the action of vit $\mathrm{D}$ to prevent the acute lung injury by blocking the Ang-2-Tie-2-MLC kinase cascade and the renin-angiotensin system, which causes massive cytokine activation. Hence, vit $\mathrm{D}$ provides the beneficial effects help improving the acute lung injury (Xu et al. 2017).

Vitamin D deficiency association has been shown related to many pathological conditions, including autoimmune diseases, cancer, diabetes, respiratory tract infections and cardiovascular diseases, and gastrointestinal aspects, suggesting the wide range of systemic symptoms in affected patients (Pludowski et al. 2013). The relationship between morbidity by infectious disorders and vitamin D level has been reported in many epidemics in the past.

Epidemiological reports indicated that vitamin D deficiency could raise the possible risk of virus infections like respiratory tract of infections and influenza (Juzeniene et al. 2010). The positive relationship of deficiency of vitamin D and viral infection is probably linked to its ability to modulation of the innate and adaptive immune system (Aranow 2011). Further studies are needed to identify the effects of vitamin D deficiency on the increased risk of COVID-19 infections.
Albumin is the most abundant and conserved protein in vertebrate's blood and is known as a reactant for an acute phase. This protein has an important function in controlling the osmotic pressure of plasma, vascular permeability, and transporting for various compounds such as cholesterol, metals, bile pigments, nitric oxide, and other molecules (Michelis et al. 2016). It has been reported that albumin also plays as a free radical scavenger for eliminating nitrogen and reactive oxygen species. In addition, it is able to induce the process of cell signaling and includes coagulatory and antiinflammatory properties. The antioxidant capacity of serum albumin under oxidative stress conditions may spoils duo to irreversible oxidation in Cys34 of serum albumin and causes cell and tissue damage. Of note, that albumin oxidation elicits neutrophil extracellular traps formation (NET) via ROS accumulation within neutrophils, which finally accumulate within the lungs (Inoue et al. 2018). Given that ROS has a pivotal role in the activation of platelet and clotting, it is predictable that both of the compartment undergoes overactivation in case of impairment in albumin. Hypoalbuminemia raised by oxidative stress/inflammation is related to thrombosis tendency and poor survival (Violi et al. 2020). This study aimed to evaluate the serum level of vitamin D and albumin in patients affected by COVID-19 compared to healthy people.

\section{Materials and methods}

\section{Patients}

The ethics committee of the Ardabil University of Medical Sciences has approved the present case-control study (IR. ARUMS.REC.1398.658), and all defined protocols were done according to the Helsinki Declaration. This clinical study was conducted for 69 days, from July 2020 to September 2020. We began observing the clinical characteristics right at the time of hospitalization of patients and their serum samples were obtained for further analysis. The total number of infected patients with COVID-19 who participated in this study was 191 . The infection of cases was confirmed by a specialist physician according to the defined clinical, laboratory detection parameters. Nasopharynx samples were obtained from clinically suspected patients for COVID-19 to evaluate further by real-time reverse transcriptase polymerase chain reaction (RT-PCR) (One-step RT-PCR Kit, Pishtaz Teb Zaman Diagnostics, Tehran, Iran).

Patients receiving supplements as treatment for chronic disease, treated with chemotherapy, dialysis patients, organ transplant recipients, and pregnant women were excluded from the study. The selected healthy individuals $(n=203)$ were studied as a control group after written informed consent. The data were obtained by analyzing the para-clinical, 
clinical tests, and taking histories. The selected patient's severity condition was considered based on symptoms such as $\mathrm{RR}$ above 30, $\mathrm{O} 2$ saturation below 93, or blood pressure below 90 .

\section{Blood sample preparation and incubation with sera}

The serum sample of COVID-19 patients (EDTA blood) was achieved from the hospital of Imam Khomeini, Ardabil, Iran. After the initial clinical tests, the control samples were taken from healthy donors (age-sex-matched). The collection of samples was carried out based on the Ardabil University of Medical Sciences Ethics Committee's published guideline after providing informed consent. The blood samples were supplied in heparin-lithium and serum-separator tubes. The samples were kept at $-80{ }^{\circ} \mathrm{C}$ till the experimental analysis.

\section{Evaluation of vitamin D level by chemiluminescence technology}

Vitamin D is known as a steroid hormone that includes two active isomers in the body (D2 and D3). D2 mainly originated from the dairy products; however, D3 can generate in the skin tissue under sunlight exposure. Vitamin D can be hydroxylated in the liver at $\mathrm{C} 25$ to generate $25-\mathrm{OH}$ vitamin D. Total 25-OH Vitamin D is defined as the whole amounts of 25-OH-D2 and 25-OH-D3 in the serum.

The level of vitamin D was measured using an automated IDS-iSYS immunoassay (Immunodiagnostic Systems Ltd, Boldon, United Kingdom). This method is used for the quantitative determination of $25(\mathrm{OH}) \mathrm{D}$, which is based on the chemiluminescence technology. The patient serum samples $(10 \mu \mathrm{l})$ are subjected to pre-treatment to denature the $25-(\mathrm{OH}) \mathrm{D}$ binding protein (VDBP). The treated samples are labeled with acridinium bound anti-25(OH) D afterwards. The biotin labeled anti-25(OH) D allowed to bind with free endogenous $25(\mathrm{OH}) \mathrm{D}$. Then, the labeled anti-25(OH) D with acridinium competes with endogenous $25(\mathrm{OH}) \mathrm{D}$ for the binding sites of antibodies. Following addition of the linked magnetic particles to streptavidin, any $25(\mathrm{OH}) \mathrm{D}$ that not bound to antibody is removed in a wash step. The resulting light emitted by the acridinium-labeled is inversely proportional to the concentration of $25(\mathrm{OH}) \mathrm{D}$ in the original sample.

\section{Measurement of serum albumin levels}

The spectrophotometric assessment of albumin was conducted with serum samples using the BCG (Bromocresol Green) albumin assay kit (Pars Azmoon, Tehran, Iran). In this assay, the selective interaction of Bromocresol Green with the molecules of albumin can generate a chromophore that is detectable at $620 \mathrm{~nm}$ wavelength. This signal is a sensitive indicator of albumin concentrations $(\mathrm{g} / \mathrm{dl})$ in the sample. Bromocresol green did not react non-specifically with other proteins and $\mathrm{IgG}$ in the test samples.

\section{Chest CT scan features}

The computed tomography (CT) scans were achieved using a 16-slice CT scanner (Siemens, Munich, Germany) for all participants with technical parameters for all considerations. Characteristics of CT scans, like lesion distribution (uni, or bilateral), central to peripheral distribution, the number of involved lobes, and also patterns of the lesion (ground-glass opacity (GGO)) and consolidation were evaluated. All the CT scan data were reviewed by an expert specialist.

\section{Statistical analysis}

Data were analyzed using SPSS version 22 using descriptive and analytical statistics. Chi-squared tests were used for categorical variables. $T$-tests or the Mann-Whitney $U$-test, ANOVA, and logistic regression were used. Odds ratios (ORs) and 95\% confidence intervals (95\% CIs) were also calculated. Statistical significance was set to $p<0.05$.

\section{Results}

\section{Demographic characteristic of the patients with COVID-19}

In this study, 191 COVID-19 patients (case) and 203 healthy (control) were investigated. The results of the present study indicated that more than $50 \%$ of the infected patients (101 individuals) were over 60 years old, and men made up a higher percentage of patients (51.3\%) (Table 1). The study of the social behaviors of the patients also showed that more than $90 \%$ of them had no addiction to narcotic drugs. As reported, $67.7 \%$ of the infected patients had comorbid conditions such as cardiovascular disease, hypertension, and diabetes mellitus. Most of the underlying diseases (Fig. 1A) were related to cardiovascular diseases, followed by hypertension and diabetes mellitus (Fig. 1B).

The performed logistic regression was analyzed to investigate the predictive role of underlying diseases associated with vitamin $\mathrm{D}$ and albumin levels. The overall results obtained in COVID-19 patients were found to be independent of their demographic characteristics, clinical signs and symptoms to apprehend the roles of these two variables at different levels (Supplementary Table 1,2). 
Table 1 Demographic characteristic of participants

\begin{tabular}{llcll}
\hline & & $\begin{array}{l}\text { Case (percent- } \\
\text { age) }\end{array}$ & $\begin{array}{l}\text { Control (percent- } \\
\text { age) }\end{array}$ & $p$ value \\
\hline Age & $<30$ & $14(7.3 \%)$ & $15(7.4 \%)$ & 0.9 \\
& $30-45$ & $29(15.2 \%)$ & $38(18.7 \%)$ & \\
& $45-60$ & $47(24.6 \%)$ & $49(24.1 \%)$ & \\
& $>60$ & $101(52.9 \%)$ & $101(52.9 \%)$ & \\
\multirow{2}{*}{ Gender } & Male & $98(51.3 \%)$ & $103(50.7 \%)$ & 0.62 \\
& Female & $93(48.7 \%)$ & $100(49.3 \%)$ & \\
Job & Employed & $41(21.5 \%)$ & - & - \\
& Unemployed & $150(78.5 \%)$ & - & - \\
\hline
\end{tabular}

\section{Symptoms assessment of the patients with COVID-19}

The symptoms assessment of the infected patients revealed that most of them had the following sings, including coughing $(60.3 \%)$, dyspnea $(60.3 \%)$, myalgia $(48.7 \%)$, weakness (56.6\%), and fever (55\%) (Table 2). In the current study, having any of the following features in the case group were considered as severe cases: (1) respiratory rate $\geq 30$ breaths per min; (2) oxygen saturation at rest $\leq 93 \%$; (3) ratio of the

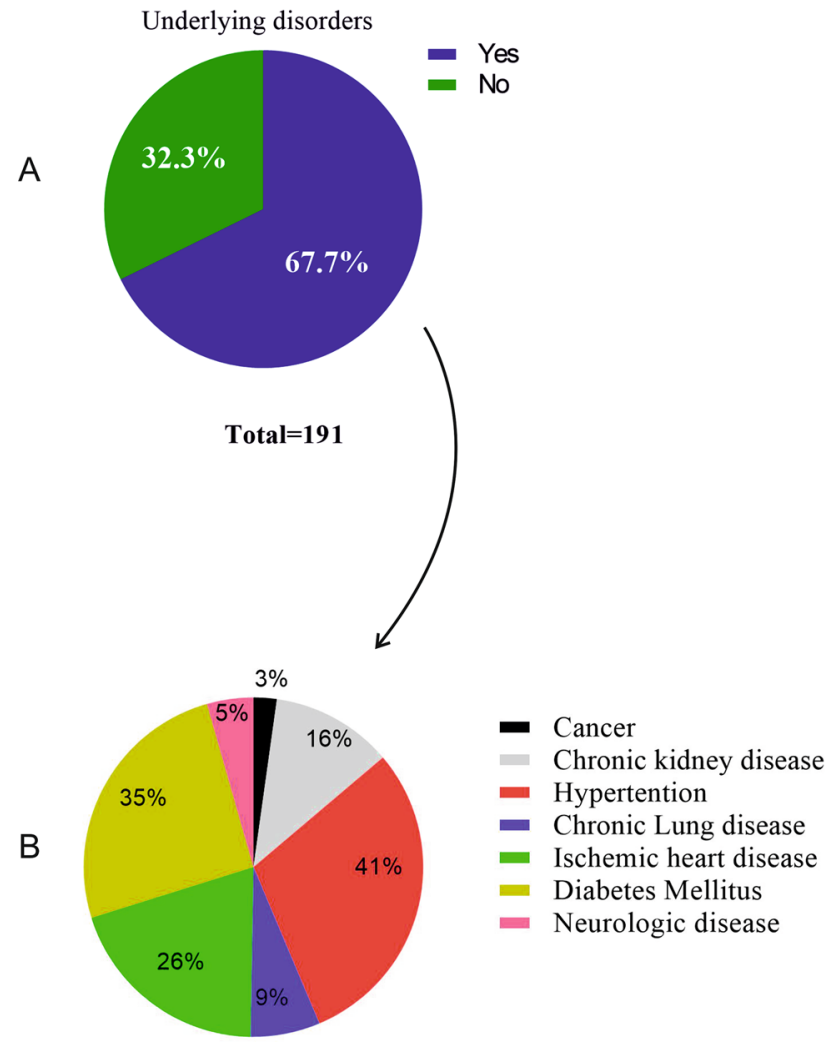

Fig. 1 Prevalence of underlying disorders in hospitalized patients with COVID-19 partial pressure of arterial oxygen to the fractional concentration of oxygen inspired air $\leq 300 \mathrm{~mm} \mathrm{Hg}$; or (4) severe disease complications (e.g., respiratory failure, the requirement of mechanical ventilation, septic shock, or non-respiratory organ failure). 142 (74.3\%) were classified as severe cases, and 49 (25.7\%) were classified as mild cases (Fig. 2).

\section{Level of vitamin D among the patients with COVID-19}

Regarding the level of vitamin D among the infected cases, the study reported that $84.4 \%$ of the patients had vitamin D deficiency and only $15.6 \%$ of the considered group had the standard level of vitamin D (Table 3). The comparison of vitamin $\mathrm{D}$ level among the control and infected groups also shows that the average level of vitamin $D$ was $26.3 \pm 0.79 \mathrm{ng} /$ $\mathrm{ml}$ and $17.6 \pm 0.81 \mathrm{ng} / \mathrm{ml}$ among the control and infected groups, respectively, which is statistically meaningful $(p<0.001)$ (Table 3 and Figs. 3, 4). A level of $<20 \mathrm{ng} / \mathrm{ml}$ $25(\mathrm{OH}) \mathrm{D}$ is considered a deficiency, between 20 and 30 as insufficiency, $>30 \mathrm{ng} / \mathrm{ml}$ is considered sufficient.

Comparison of the distribution of patients in different groups in terms of vitamin D levels also showed that the case and control groups have significant differences in terms of being in different levels of vitamin $\mathrm{D}(p<0.001)$. In contrast to $109(57.1 \%)$ individuals in the case group with severe

Table 2 The proportion of clinical symptoms and signs

\begin{tabular}{|c|c|c|c|}
\hline Symptoms & & $\begin{array}{l}\text { Number of } \\
\text { patients } \\
\text { Number }\end{array}$ & $\begin{array}{l}\text { Percentage } \\
\text { of patients } \\
\text { Percent }\end{array}$ \\
\hline \multirow{4}{*}{$\begin{array}{l}\text { Gastrointestinal } \\
\text { features }\end{array}$} & Vomiting & 34 & $18 \%$ \\
\hline & Abdomen pain & 30 & $15.9 \%$ \\
\hline & Nausea & 49 & $22.2 \%$ \\
\hline & Diarrhea & 41 & $21.7 \%$ \\
\hline \multirow{7}{*}{$\begin{array}{l}\text { Respiratory } \\
\text { features }\end{array}$} & Cough & 114 & $60.3 \%$ \\
\hline & Dyspnea & 114 & $60.3 \%$ \\
\hline & ARDS & 39 & $20.7 \%$ \\
\hline & Rhinorrhea & 20 & $10.6 \%$ \\
\hline & Hemoptysis & 5 & $2.6 \%$ \\
\hline & Pharyngitis & 48 & $25.4 \%$ \\
\hline & Chest pain & 58 & $30.7 \%$ \\
\hline \multirow[t]{6}{*}{ Systemic features } & Fever & 104 & $55 \%$ \\
\hline & Loss of appetite & 77 & $40.7 \%$ \\
\hline & Shock & 5 & $2.6 \%$ \\
\hline & Fatigue & 63 & $33.3 \%$ \\
\hline & Weakness & 107 & $56.6 \%$ \\
\hline & Myalgia & 92 & $48.7 \%$ \\
\hline \multirow{3}{*}{$\begin{array}{l}\text { Neurology fea- } \\
\text { tures }\end{array}$} & Anosmia & 15 & $7.9 \%$ \\
\hline & Agitation & 19 & $10.1 \%$ \\
\hline & Headache & 64 & $33.9 \%$ \\
\hline
\end{tabular}




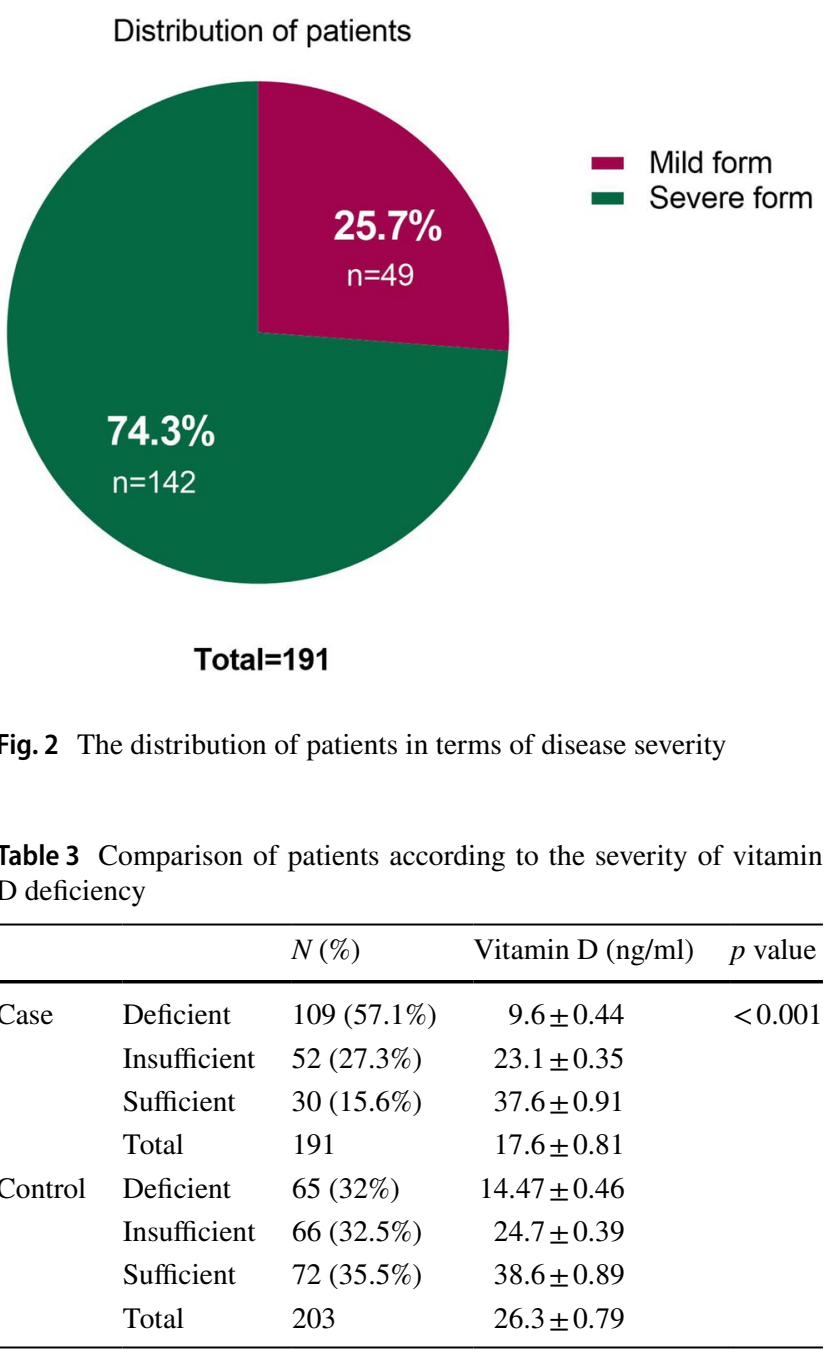

vitamin D deficiency, only 65 (32\%) individuals in the control group had this vitamin D deficiency level. In addition, by the contrast of $72(35.5 \%)$ people in the control group who were in the optimal category of vitamin D levels, only $30(15.6 \%)$ people in the case group had the desired level of vitamin D (Table 3).

The evaluation of mean vitamin $\mathrm{D}$ at different levels of vitamin $\mathrm{D}$ deficiency and comparison between case and control groups showed that mean vitamin D levels in patients with inappropriate vitamin D levels $(9.6 \pm 0.44 \mathrm{ng} / \mathrm{ml})$ compared to the same level in the control group $(14.47 \pm 0.46 \mathrm{ng} / \mathrm{ml})$ were significantly low. A statistically significant difference was obtained between the two groups $(p<0.001)$ (Table 3$)$.

Estimating the odds ratio of studied groups $(\mathrm{OR}=2.95$, CI 1.8-4.7) indicated that those patients who are suffering from vitamin D deficiency have more chance to be infected by COVID-19 (approximately three times) than the control

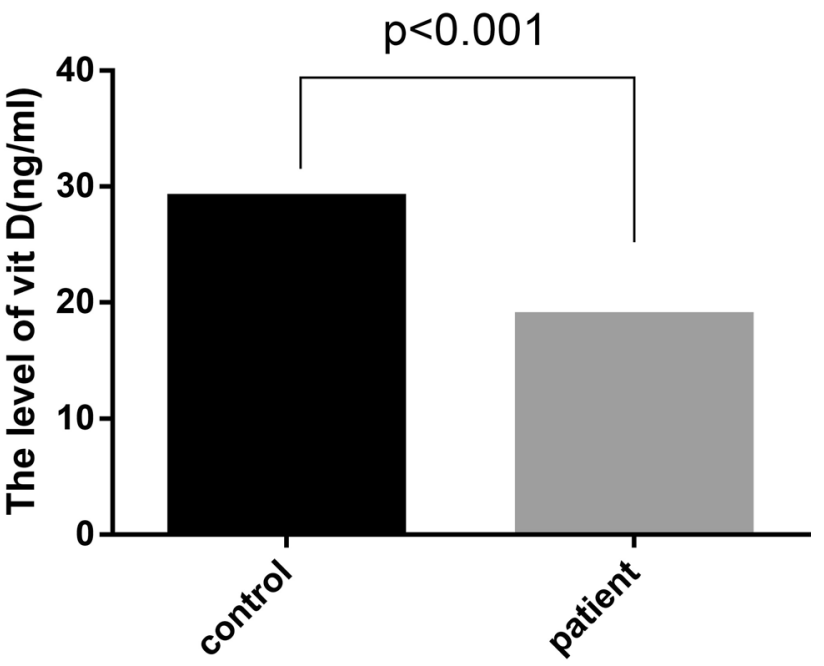

Fig. 3 The comparison of vitamin D level among the patients with COVID-19 and control

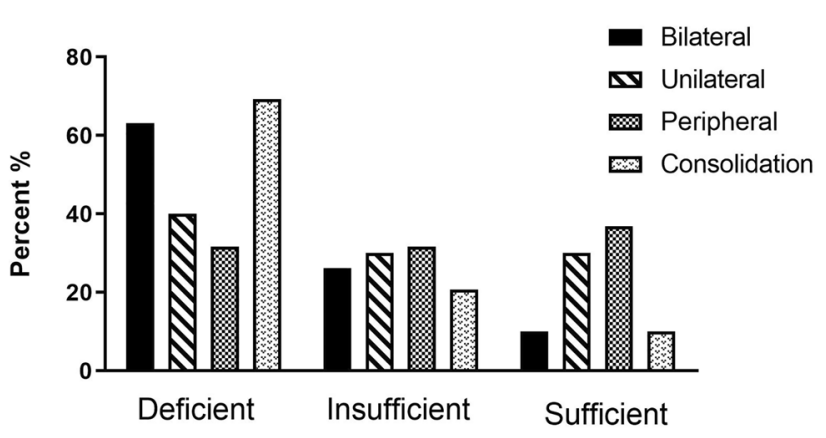

Fig. 4 Association of vitamin D status with lung involvement in patients with COVID-19

group. The vitamin D levels of the patients addicted to narcotic drugs also were tested, and the results were not shown as considerable difference $(p=0.56)$. Furthermore, there was a meaningful difference among the patients with and without respiratory symptoms $(p=0.03)$, but there was not seen meaningful difference among the patients with and without gastrointestinal symptoms $(p=0.49)$.

\section{Level of albumin among the patients with COVID-19}

The average level of albumin in case of COVID-19 patients was found to be around $\sim 3.94 \mathrm{~g} / \mathrm{dl}$. The amount of albumin was decreased in patients $(3.7 \pm 0.59 \mathrm{~g} / \mathrm{dl})$ showing intubation status as compared to the patients $(4.1 \pm 0.67)$ showing no intubation status ( $p=0.004)$ (Table 4$)$. Of note, the average level of albumin was significantly decreased in those infected who had respiratory symptoms, while there was no 
Table 4 Level of albumin among the patients with COVID-19

\begin{tabular}{lccc}
\hline & & Albumin $(\mathrm{g} / \mathrm{dl})$ & $p$ value \\
\hline Patients with respiratory symptoms & Yes & $4.05 \pm 0.64$ & 0.04 \\
& No & $4.29 \pm 0.76$ & \\
Patients with digestive symptoms & Yes & $4.06 \pm 0.71$ & 0.32 \\
& No & $4.17 \pm 0.59$ & \\
Intubation status & Yes & $3.7 \pm 0.59$ & 0.004 \\
& No & $4.1 \pm 0.67$ & \\
\hline
\end{tabular}

relationship between the severity of infection and gastrointestinal symptoms.

Moreover, analysis of albumin levels with disease severity at different levels of vitamin D showed that in sufficient levels of vitamin $\mathrm{D}$, there was a positive association between albumin levels and disease severity, but this difference was not statistically significant $(\mathrm{OR}=1.12$; CI $0.39-3.2)$ (Table 5).

\section{CT chest findings in patients infected with COVID-19}

Of the 191 patients, as presented in (Fig. 5), (Table 6), most patients had bilateral 141 (74\%) and multifocal lung involvement, and 29 (15.2\%) had consolidation. Most of the patients had involvement of three lobes 54 (28.3\%). Considering the location of the lung lesions, most patients had posterior lesions. The vitamin $\mathrm{D}$ and albumin levels evaluated according to CT chest findings in patients with COVID-19. Our result showed a significant difference between vitamin $\mathrm{D}$ and albumin levels and bilateral, multi lobular consolidation pattern and the number of affected lobes in COVID-19 patients.

The mean vitamin $\mathrm{D}$ level in the patient who had consolidation pattern or pure ground-glass opacities (GGO) were $11.1 \pm 1.37 \mathrm{ng} / \mathrm{ml}$ and $18.89 \pm 0.89 \mathrm{ng} / \mathrm{ml}$, respectively. The mean vitamin D level were $31.26 \pm 2.48 \mathrm{ng} / \mathrm{ml}$ in COVID-19 patient with one lobe involvement, $22.22 \pm 1.29 \mathrm{ng} / \mathrm{ml}$ with two-lobe involvement, $15.53 \pm 1.25 \mathrm{ng} / \mathrm{ml}$ with three-lobe involvement, $12.7 \pm 1.76 \mathrm{ng} / \mathrm{ml}$ with four-lobe involvement, and $11.82 \pm 0.81$ with five lobe involvement. The mean vitamin D level was lowest in patient with all five lobes of lung involvement. So, sufficient levels of vitamin D (>30 ng/
Table 5 The relationship between albumin levels and disease severity at different levels of vitamin D

\begin{tabular}{lllllll}
\hline Vit D level $(\mathrm{ng} / \mathrm{ml})$ & B & S.E. & Sig. & Exp (B) & \multicolumn{2}{l}{ 95\% C.I. for EXP(B) } \\
\cline { 5 - 7 } & & & & & Lower & Upper \\
\hline Deficient & -0.001 & 0.292 & 0.997 & 0.999 & 0.564 & 1.771 \\
Insufficient & -0.509 & 0.562 & 0.365 & 0.601 & 0.200 & 1.807 \\
Sufficient & 0.117 & 0.538 & 0.828 & 1.124 & 0.392 & 3.228 \\
\hline
\end{tabular}

A

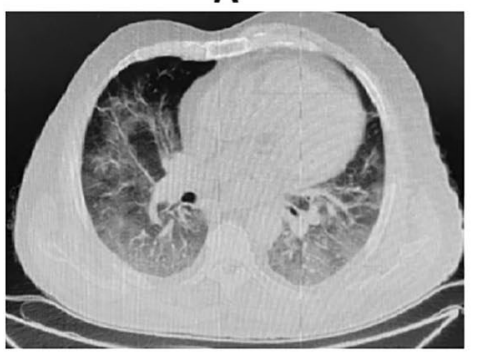

D

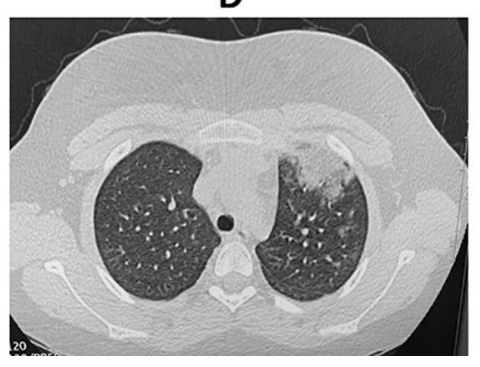

B

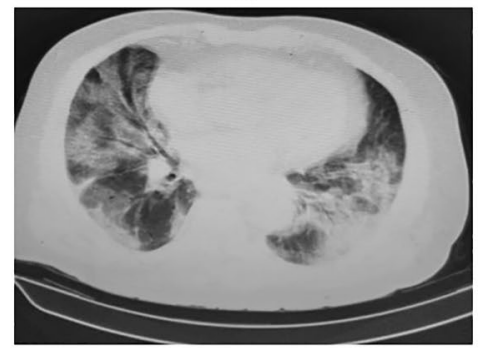

E

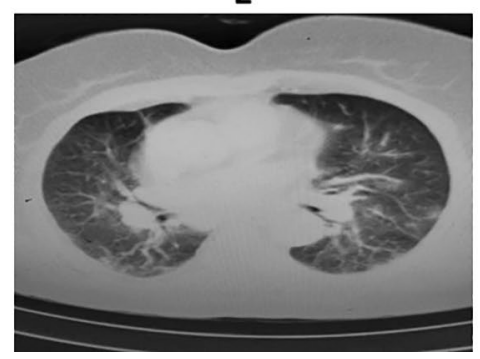

C

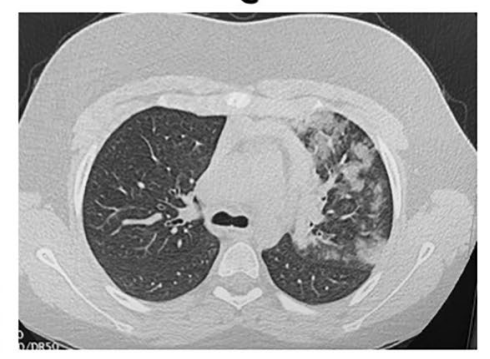

F

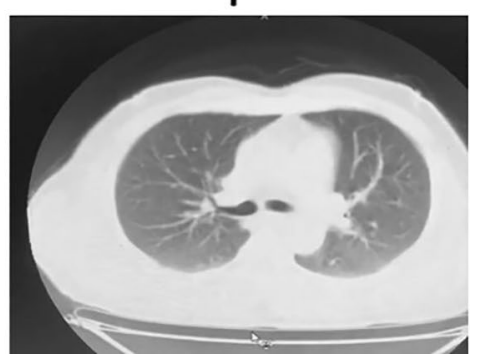

Fig. 5 Lung computed tomography (CT) images of COVID-19 pneumonia in patient with vit D deficiency. A Bilateral involvement, B consolidation and GGO, $\mathbf{C}$ unilateral involvement, $\mathbf{D}$ consolidation, $\mathbf{E}$ pure GGO, and $\mathbf{F}$ healthy individual 
Table 6 Level of Vit D and albumin in lung involvement

\begin{tabular}{|c|c|c|c|c|c|}
\hline Variable & Yes/no, Number (\%) & Level of vit D (ng/ml) & $p$ value & Level of albumin $(\mathrm{g} / \mathrm{dl})$ & $p$ value \\
\hline \multirow[t]{2}{*}{ Bilateral involvement } & Yes, $141(74 \%)$ & $16.00 \pm 1.79$ & \multirow[t]{2}{*}{$<0.001$} & $3.9 \pm 0.68$ & \multirow[t]{2}{*}{$<0.001$} \\
\hline & No, $50(26 \%)$ & $22.54 \pm 0.85$ & & $4.43 \pm 0.58$ & \\
\hline \multirow[t]{2}{*}{ Unilateral involvement } & Yes, $50(26 \%)$ & $22.54 \pm 0.85$ & \multirow[t]{2}{*}{$<0.001$} & $4.43 \pm 0.58$ & \multirow[t]{2}{*}{$=0.001$} \\
\hline & No, $141(74 \%)$ & $16.00 \pm 1.79$ & & $3.9 \pm 0.68$ & \\
\hline \multirow[t]{2}{*}{ Peripheral involvement } & Yes, $38(19.9 \%)$ & $25.34 \pm 1.95$ & \multirow[t]{2}{*}{$<0.001$} & $4.42 \pm 0.56$ & \multirow[t]{2}{*}{$=0.001$} \\
\hline & No, $153(80.1 \%)$ & $15.81 \pm 0.82$ & & $4.02 \pm 0.68$ & \\
\hline \multirow[t]{2}{*}{ Consolidation } & Yes, $29(15.2 \%)$ & $11.1 \pm 1.37$ & \multirow[t]{2}{*}{$<0.001$} & $3.7 \pm 0.69$ & \multirow[t]{2}{*}{$=0.003$} \\
\hline & No, $162(84.8 \%)$ & $18.89 \pm 0.89$ & & $4.1 \pm 0.66$ & \\
\hline \multirow[t]{2}{*}{ Pure GGO } & Yes, $162(84.8 \%)$ & $18.89 \pm 0.89$ & \multirow[t]{2}{*}{$<0.001$} & $4.1 \pm 0.66$ & \multirow[t]{2}{*}{$=0.003$} \\
\hline & No, $29(15.2 \%)$ & $11.1 \pm 1.37$ & & $3.7 \pm 0.69$ & \\
\hline \multicolumn{6}{|l|}{ Number of affected lobe } \\
\hline 1 & $19(9.9 \%)$ & $31.26 \pm 2.48$ & \multirow[t]{5}{*}{$<0.001$} & $4.46 \pm 0.58$ & \multirow[t]{5}{*}{$<0.001$} \\
\hline 2 & $50(26.2 \%)$ & $22.22 \pm 1.29$ & & $4.34 \pm 0.63$ & \\
\hline 3 & $54(28.3 \%)$ & $15.53 \pm 1.25$ & & $4.08 \pm 0.62$ & \\
\hline 4 & $40(20.9 \%)$ & $12.7 \pm 1.76$ & & $3.95 \pm 0.7$ & \\
\hline 5 & $28(14.7 \%)$ & $11.82 \pm 0.81$ & & $4.1 \pm 0.68$ & \\
\hline
\end{tabular}

$\mathrm{ml}$ reduced the number of affected lung lobes and consolidation pattern in patients diagnosed with COVID-19. The mean albumin level for consolidation and pure GGO were $3.7 \pm 0.69 \mathrm{~g} / \mathrm{dl}$ and $4.1 \pm 0.66 \mathrm{~g} / \mathrm{dl}$, respectively. The mean albumin level were $4.46 \pm 0.58 \mathrm{~g} / \mathrm{dl}$ in COVID-19 patient with one lobe involvement, $4.34 \pm 0.63 \mathrm{~g} / \mathrm{dl}$ with two-lobe involvement, $4.08 \pm 0.62 \mathrm{~g} / \mathrm{dl}$ with three-lobe involvement, $3.95 \pm 0.7 \mathrm{~g} / \mathrm{dl}$ with four-lobe involvement, and $4.1 \pm 0.68 \mathrm{~g} /$ dl with five lobe involvement (Fig. 4) (Table 6).

Regression analysis for determining predictive factors and evaluation of vitamin D deficiency on lung involvement indicated that subjects in the vitamin D deficiency group are 4.4 times more likely to develop bilateral involvement than those in the vitamin D sufficient group $(p<0.001)$. In addition, analysis showed that differences in vitamin D level had no predictive effect on consolidation involvement (Table 7).

\section{Discussion}

The SARS-CoV-2 coronavirus provokes a significant range of symptomatic and asymptomatic manifestations through mechanisms including infection-induced lymphopenia, cytokine storm, and hematopathology effects lead to the progress of the infection in multiple organs of the body (Nikolich-Zugich et al. 2020).

In this study, we recognized variations in demographic information, laboratory tests, clinical manifestations, and therapeutic approaches on the severity outcomes of the disease in COVID-19 patients. The most important outcome of our study is that there is a direct association of vitamin $\mathrm{D}$
Table 7 Regression analysis for determining predictive factors

\begin{tabular}{lllll}
\hline & Sig & B & \multicolumn{2}{l}{$\begin{array}{l}\text { 95\% CI for } \\
\text { EXP(B) }\end{array}$} \\
\cline { 4 - 6 } & & & Lower & Upper \\
\hline Bilateral & & & & \\
$\quad$ Deficient level of vit D & 0.001 & 4.450 & 1.875 & 10.564 \\
$\quad$ Insufficient level of vit D & 0.058 & 2.467 & 0.969 & 6.276 \\
Peripheral & & & & \\
$\quad$ Deficient level of vit D & 0.000 & 0.141 & 0.056 & 0.360 \\
Insufficient level of vit D & 0.030 & 0.343 & 0.131 & 0.900 \\
\hline
\end{tabular}

deficiency with the severity of COVID-19. Of note, vitamin D Deficiency was associated with respiratory involvement. A significant difference was established among the patients presented with or without the respiratory symptoms. But such correlation did not exist among those who observed with gastrointestinal symptoms. Nevertheless, vitamin D deficiency could be related to other gastrointestinal diseases, e.g., inflammatory bowel disease and colorectal cancer (Raman et al. 2011).

We found that low vitamin D levels at baseline were associated with a significantly higher rate of infection by SARSCoV-2 compared with the healthy control group. Vitamin D level adjusting is essential for demographic variables using signs and symptoms of patients with COVID-19. The overall findings suggest that vitamin D produces an immunomodulatory effect on the COVID-19 disease benefited patients who have shown poor prognosis of the disease. According to the Institute of Medicine committee, a serum level 
of $25(\mathrm{OH}) \mathrm{D} 3$ less than $20 \mathrm{ng} / \mathrm{ml}(50 \mathrm{nmol} / \mathrm{l})$ is defined as vitamin D deficiency (Lee 2020; Ross et al. 2011).

Recent studies suggested that the hypovitaminosis D is associated with various viral infections including HIV, HPV and HCV (Melo-Villar et al. 2015; Orell-Kotikangas et al. 2012; Vescini et al. 2011). We have also obtained the similar results. Accumulated evidence on these findings have disclosed a significant correlation between decreased vitamin D level and bad prognosis of COVID-19 disease associated with mortality (Ilie et al. 2020). D'Avolio et al. in a retrospective study indicated that of 107 patients who participated in the study vitamin D levels in COVID-19-positive patients were significantly decreased (D'Avolio et al. 2020). Another study reported that $67.2 \%$ of the patients with COVID-19 had vitamin D levels of less than $30 \mathrm{ng} / \mathrm{ml}$ (Maghbooli et al. 2020).

The vitamin D plays an important role to regulate the immunological mechanisms in viral infections. Vitamin D and its functional receptors VDR are the active regulators for the expression of VDRGS (vitamin D-related genes) to control the adaptive and innate immune responses (Kho et al. 2013).

According to our study, the COVID-19 patients have reached out to critical conditions due to vitamin D deficiency, and would have resulted in the formation of hyperinflammatory state the 'cytokine storm'. Vitamin D deficiency in SARS-CoV-2 infections leads to secrete various cytokines, low peripheral $\mathrm{CD}+4 \mathrm{~T}$ cells, and may cause the severe pulmonary fibrosis, eventually direct the poor prognosis with lower survival rates in patients (Rothan and Byrareddy 2020). Vitamin D can inhibit the maturation phase in dendritic cells, thus inhibiting excessive inflammatory response to progression in infectious diseases (Sassi et al. 2018).

Conversely, our finding showed that a high level of vitamin D had been associated with probable and natural resistance and protection against COVID-19 disease. According to SA Lanham-New and coworkers, supplementation and restoration of vitamin $\mathrm{D}$ products to normal values in coronavirus-infected patients may improve outcomes of the disease and immune-related response combination with other antiviral therapies Li et al. 2020a, b, c). Vitamin D may protect against the progression of downstream molecular pathways toward mortalities due to SARS-CoV-2-infected patients.

People who have limited natural sunlight exposure are unlikely to obtain adequate vitamin $\mathrm{D}$ from sunlight, which may impact on high prevalence of vitamin $\mathrm{D}$ deficiency followed by a high rate of viral infections or high mortality rate from such pandemics, including SARS-CoV-2. Natalia Alvarez et al. have not only provided the attention to use vitamin D resources to protect against the viral infections, but also given the considerations to define the adequate supplementation protocol for patients (Alvarez et al. 2019).

Pneumonia caused by SARS, MERS, and COVID-19 have some common features, such as the prevalence of bilateral peripheral GGO pattern involvement (Ajlan et al. 2014; Wong et al. 2003). According to reports, in the early phase of SARS, and MERS the most common feature was unilateral involvement; however, it was not a common result in our study, and we observed bilateral and multilobular involvement. GGO is the most common CT feature of patients with COVID-19 pneumonia that could detectable in patients a few days after the beginning of the disease ( $\mathrm{Li}$ et al. 2020a, b, c). In our study, compared to a patient with deficient vitamin D levels $(<20 \mathrm{ng} / \mathrm{ml})$, in the group with sufficient vitamin D level of (>30 ng/ml), low intensity of lung involvement was observed.

Giving that ACE-2 considered an entrance way for SARSCoV-2 and downregulated ACE-2 expression as infecting the cells, it stated that viruses preventing ACE-2 receptors to perform their physiological functions and resulting in lung disorders. Xu et al. indicated that the supplementation of vitamin D through modulating the expression of ACE-2 offers a protective effect on acute lung injury ( $\mathrm{Xu}$ et al. 2017). Thus, vitamin D directly impacts on lung tissue and improves acute respiratory system injury may be through ACE-2. It can, therefore, be stated that COVID-19 incidence was higher among the subjects with severe vitamin D deficiency. The result showed a positive correlation between vitamin D deficiency and of COVID-19 infection that was in line with other studies evaluating the relationships between vitamin D deficiency and COVID-19 infections.

According to our findings, there was a significantly decreased level of serum albumin in patients with COVID19. Our finding is confirmed by several related researches on effects of serum albumin in viral infected patients. Sahera Dirajlal-Fargo et al. suggested lower serum albumin related to high hypercoagulation and chronic inflammation in immune-deficiency events such as Human Immunodeficiency Virus Infection (Dirajlal-Fargo et al. 2018).

Our finding showed that the average level of albumin was significantly decreased in SARS-CoV-2-infected patients, which had severe respiratory symptoms, while we did not observe a relationship between the severity of the infection and gastrointestinal symptoms. Juyi Li et al. 2020a, b, c have also shown that plasma levels of platelet and albumin significantly associated with the severity of COVID-19 and even be a risk factor for predicting for non-survival in critical patients with COVID-19 (Li et al. 2020a, b, c). Our study suggests that serum vitamin profile should be tested in the wider case-control studies. Clinical trials and case-control studies could be designed to determine the relative effect of vitamin D supplementation and its combination with other vitamins, e.g., vitamin A and receptor antagonists. 


\section{Conclusion}

The overall results in our case-control study have shown that a significant negative correlation is established in between the mean vitamin D level and the severity of COVID-19 disease. Therefore, it is concluded that the immunomodulatory and anti-inflammatory effects of vitamin D potentially contribute to inhibit the viral replication in the body, to confer the direct protection against the infection. Our findings strongly suggest that the adequate level $(\geq 20$ to $\leq 50 \mu \mathrm{g} / \mathrm{ml}$ ) of vitamin $\mathrm{D}$ is associated with probable and natural resistance against the COVID-19 disease.

Supplementary Information The online version contains supplementary material available at https://doi.org/10.1007/s00203-021-02482-5.

Acknowledgements The authors would like to thank the Ardabil University of Medical Sciences, Ardabil, Iran, for financial support and making their laboratory facilities and equipment available to us for this project.

Author contributions SM, NF, and ES conceived and planned the study; VA, HAK, and MN carried out the experiment and collected the available literature; YP and SM and ES prepared the manuscript, analyzed the statistical data and verified the accuracy of the tests.

\section{Declarations}

Conflict of interest The authors declare that there is no conflict of interest. The authors alone are responsible for the accuracy and integrity of the paper content.

\section{References}

Ajlan AM, Ahyad RA, Jamjoom LG, Alharthy A, Madani TA (2014) Middle East respiratory syndrome coronavirus (MERS-CoV) infection: chest CT findings. Am J Roentgenol 203(4):782-787

Alvarez N, Aguilar-Jimenez W, Rugeles MT (2019) The potential protective role of vitamin D supplementation on HIV-1 infection. Front Immunol 10:2291

Aranow C (2011) Vitamin D and the immune system. J Investig Med 59(6):881-886

Baeke F, Takiishi T, Korf H, Gysemans C, Mathieu C (2010) Vitamin D: modulator of the immune system. Curr Opin Pharmacol 10(4):482-496

D’Avolio A, Avataneo V, Manca A, Cusato J, De Nicolò A, Lucchini $\mathrm{R}$ et al (2020) 25-Hydroxyvitamin D concentrations are lower in patients with positive PCR for SARS-CoV-2. Nutrients 12(5):1359

Dirajlal-Fargo S, Kulkarni M, Bowman E, Shan L, Sattar A, Funderburg N, McComsey GA (2018) Serum Albumin is associated with higher inflammation and carotid atherosclerosis in treated human immunodeficiency virus infection. Open Forum Infect Dis. https://doi.org/10.1093/ofid/ofy291

Ilie PC, Stefanescu S, Smith L (2020) The role of vitamin D in the prevention of coronavirus disease 2019 infection and mortality. Aging Clin Exp Res 32(7):1195-1198

Inoue M, Nakashima R, Enomoto M, Koike Y, Zhao X, Yip K et al (2018) Plasma redox imbalance caused by albumin oxidation promotes lung-predominant NETosis and pulmonary cancer metastasis. Nat Commun 9(1):1-11

Juzeniene A, Ma L-W, Kwitniewski M, Polev GA, Lagunova Z, Dahlback A, Moan J (2010) The seasonality of pandemic and non-pandemic influenzas: the roles of solar radiation and vitamin D. Int J Infect Dis 14(12):e1099-e1105

Kho AT, Sharma S, Qiu W, Gaedigk R, Klanderman B, Niu S et al (2013) Vitamin D related genes in lung development and asthma pathogenesis. BMC Med Genomics 6(1):1-9

Kupferschmidt K, Cohen J (2020) Race to find COVID-19 treatments accelerates. In: American Association for the Advancement of Science

Lai C-C, Shih T-P, Ko W-C, Tang H-J, Hsueh P-R (2020) Severe acute respiratory syndrome coronavirus 2 (SARS-CoV-2) and coronavirus disease-2019 (COVID-19): the epidemic and the challenges. Int J Antimicrobial Agents 55(3):105924

Lee C (2020) Controversial effects of vitamin D and related genes on viral infections, pathogenesis, and treatment outcomes. Nutrients 12(4):962

Li J, Li M, Zheng S, Li M, Zhang M, Sun M et al (2020a) Plasma albumin levels predict risk for nonsurvivors in critically ill patients with COVID-19. Biomark Med 14(10):827-837

Li J, Wang X, Chen J, Zhang H, Deng A (2020b) Association of renin-angiotensin system inhibitors with severity or risk of death in patients with hypertension hospitalized for coronavirus disease 2019 (COVID-19) infection in Wuhan, China. JAMA Cardiol 5(7):825-830

Li K, Wu J, Wu F, Guo D, Chen L, Fang Z, Li C (2020c) The clinical and chest CT features associated with severe and critical COVID-19 pneumonia. Invest Radiol

Maghbooli Z, Sahraian MA, Ebrahimi M, Pazoki M, Kafan S, Tabriz $\mathrm{HM}$ et al (2020) Vitamin D sufficiency, a serum 25-hydroxyvitamin $\mathrm{D}$ at least $30 \mathrm{ng} / \mathrm{mL}$ reduced risk for adverse clinical outcomes in patients with COVID-19 infection. PLoS ONE 15(9):e0239799

Melo-Villar L, Lampe E, De Almeida AJ, de P Scalioni L, LewisXimenez LL, Miguel JC et al (2015) Hypovitaminosis D and its relation to demographic and laboratory data among hepatitis $\mathrm{C}$ patients. Ann Hepatol 14(4):457-463

Michelis R, Sela S, Zeitun T, Geron R, Kristal B (2016) Unexpected normal colloid osmotic pressure in clinical states with low serum albumin. PLoS ONE 11(7):e0159839

Nikolich-Zugich J, Knox KS, Rios CT, Natt B, Bhattacharya D, Fain MJ (2020) SARS-CoV-2 and COVID-19 in older adults: what we may expect regarding pathogenesis, immune responses, and outcomes. Geroscience 42(2):505-514

Orell-Kotikangas H, Schwab U, Österlund P, Saarilahti K, Mäkitie O, Mäkitie AA (2012) High prevalence of vitamin D insufficiency in patients with head and neck cancer at diagnosis. Head Neck 34(10): 1450-1455

Pludowski P, Holick MF, Pilz S, Wagner CL, Hollis BW, Grant WB et al (2013) Vitamin D effects on musculoskeletal health, immunity, autoimmunity, cardiovascular disease, cancer, fertility, pregnancy, dementia and mortality - a review of recent evidence. Autoimmun Rev 12(10):976-989

Raman M, Milestone AN, Walters JR, Hart AL, Ghosh S (2011) Vitamin $\mathrm{D}$ and gastrointestinal diseases: inflammatory bowel disease and colorectal cancer. Ther Adv Gastroenterol 4(1):49-62

Ross AC, Manson JE, Abrams SA, Aloia JF, Brannon PM, Clinton SK et al (2011) The 2011 report on dietary reference intakes for calcium and vitamin D from the Institute of Medicine: what clinicians need to know. J Clin Endocrinol Metab 96(1):53-58

Rothan HA, Byrareddy SN (2020) The epidemiology and pathogenesis of coronavirus disease (COVID-19) outbreak. J Autoimmunity 109:102433 
Samuel S, Sitrin MD (2008) Vitamin D's role in cell proliferation and differentiation. Nutr Rev 66(suppl_2):S116-S124

Sassi F, Tamone C, D’Amelio P (2018) Vitamin D: nutrient, hormone, and immunomodulator. Nutrients 10(11):1656

Vescini F, Cozzi-Lepri A, Borderi M, Re MC, Maggiolo F, De Luca A et al (2011) Prevalence of hypovitaminosis D and factors associated with vitamin D deficiency and morbidity among HIV-infected patients enrolled in a large Italian cohort. JAIDS J Acquired Immune Defic Syndr 58(2):163-172

Violi F, Cangemi R, Romiti GF, Ceccarelli G, Oliva A, Alessandri F et al (2020) Is albumin predictor of mortality in COVID-19? Antioxid Redox Signal 35:139

Wong K, Antonio GE, Hui DS, Lee N, Yuen EH, Wu A et al (2003) Thin-section CT of severe acute respiratory syndrome: evaluation of 73 patients exposed to or with the disease. Radiology 228(2):395-400
Wu C, Zheng M (2020) Single-cell RNA expression profiling shows that ACE2, the putative receptor of Wuhan 2019-nCoV, has significant expression in the nasal, mouth, lung and colon tissues, and tends to be co-expressed with HLA-DRB1 in the four tissues

Xu J, Yang J, Chen J, Luo Q, Zhang Q, Zhang H (2017) Vitamin D alleviates lipopolysaccharide-induced acute lung injury via regulation of the renin-angiotensin system. Mol Med Rep 16(5):7432-7438

Zittermann A, Pilz S, Hoffmann H, März W (2016) Vitamin D and airway infections: a European perspective. Eur J Med Res 21(1):1-10

Publisher's Note Springer Nature remains neutral with regard to jurisdictional claims in published maps and institutional affiliations. 